Published online 2017 April 13.

Abstract

\title{
Imaging of Vascular Lesions in Pediatric
}

\section{Houman Alizadeh ${ }^{1, *}$}

${ }^{1}$ CHMC, Tehran University of Medical Sciences

"Corresponding author: Houman Alizadeh, MD, CHMC, Tehran University of Medical Sciences. E-mail: houmanalizadeh68@gmail.com

Received 2016 December 21; Accepted 2017 February 08.

\begin{abstract}
The most common soft tissue tumors during infancy and childhood are vascular lesions. Although the vast majority of these lesions have typical clinical features and do not require any further exam, but sometimes atypical superficial or deeply located lesions need complementary studies to be diagnosed and classified. In that way it is also very important to exclude very less common malignant soft tumors. Imaging studies play an essential role for categorization of vascular lesions. Vascular tumors such as hemangiomas and vascular malformations have their own imaging characteristics to be classified. Although MRI is the best imaging modality because of its excellent soft tissue resolution, but ultrasound and color Doppler studies are the first step and sometimes preferred imaging approach in most of the cases. This is a review article to describe the various imaging findings of different types of vascular lesions in childhood and infancy.
\end{abstract}

This is an abstract presented in the 33rd Iranian congress of radiology (ICR) and the 15th congress of Iranian radiographic science association (IRSA). 